\title{
Determination of dimensions of Glenoid cavity from other scapular parameters in North Indian Population
}

Seema Sehmi ${ }^{* 1}$, Anupama Mahajan ${ }^{2}$.

${ }^{*}$ Professor, Department of Anatomy, Sri Guru Ram Das Institute of Medical Sciences and Research, Vallah, Amritsar, Punjab, India.

${ }^{2}$ Professor and Head, Department of Anatomy Sri Guru Ram Das Institute of Medical Sciences and Research, Vallah, Amritsar, Punjab, India.

\section{ABSTRACT}

Background: The Glenoid cavity dimensions can help to predict the incidence of glenohumeral dislocations in a population.

Purpose of study: The present study involved the measurements of the body of the scapula and the glenoid cavity and to draw the relationship of them to predict the chances of glenohumeral dislocations in North Indian Population.

Methods: A total number of 130 adult scapulae of unknown sex showing complete ossification and without any damage were included in the study. The various shapes of glenoid cavities both on right and left sides were noted and analysed. A digital Vernier calliper was used to measure all the dimensions of scapula as well as glenoid cavity. The data was analysed and regression formulae to estimate the glenoid cavity dimensions were drawn.

Results: Most common shape of the glenoid cavity in the present study was pear shaped (52.30\%) followed by inverted comma shaped (33.07\%) and least common was oval shaped (14.63\%). Mean maximum height of scapula (MSH) was $142.45 \pm 2.32 \mathrm{~mm}$, mean maximum width of scapula (MSW) was $102.65 \pm 0.21 \mathrm{~mm}$. Mean maximum glenoid height (MGH) was $38.77 \pm 3.15 \mathrm{~mm}$, mean maximum glenoid width I (MGW I) was 23.82 $2.11 \mathrm{~mm}$, mean maximum glenoid width II ( MGW II) was $14.78 \pm 9.11 \mathrm{~mm}$. Mean scapular index (SI) was $71.32 \pm$ $0.61(60-<73) \%$ and mean glenoid index (GI) was 60.43 $\pm 5.43 \%$ ( 60-69\%). Bilateral differences in these parameters were statistically insignificant. Mean maximum scapular height was significantly correlated with both mean maximum glenoid height and mean maximum glenoid width. There was also found highly significant interglenoid dimension correlation.

Conclusion: Glenohumeral dislocations are expected if indices are $<50 \%$ or $>89 \%$. A deviation from the normal relation between maximum glenoid width and maximum glenoid length also indicates glenohumeral instability.

KEY WORDS: Glenoid cavity, Gleno humeral, Scapula.

Corresponding Author: Dr. Seema Sehmi, Professor, Department of Anatomy, Sri Guru Ram Das Institute of Medical Sciences and Research, Vallah, Amritsar, Punjab, India.

E-Mail: drseema16@gmail.com

\begin{tabular}{|c|c|}
\hline Access this Article online & Journal Information \\
\hline \multirow{3}{*}{ Quick Response code } & $\begin{array}{l}\text { International Journal of Anatomy and Research } \\
\text { ISSN (E) 2321-4287 | ISSN (P) 2321-8967 } \\
\text { https://www.ijmhr.org/ijar.htm } \\
\text { DOI-Prefix: https://dx.doi.org/10.16965/ijar } \quad \text { (cc) E ET-No-si }\end{array}$ \\
\hline & Article Information \\
\hline & $\begin{array}{l}\text { Accepted: } 04 \text { Jan } 2022 \\
\text { Published (O): } 05 \text { Mar } 2022 \\
\text { Published (P): } 05 \text { Mar } 2022\end{array}$ \\
\hline
\end{tabular}

\section{INTRODUCTION}

The role of scapula in shoulder instability, rotator cuff disease and shoulder impingement can not be underestimated [1]. At the lateral angle of scapula lies pear shaped glenoid cavity which articulates with the head of the humerus to form shoulder joint. The morphometric study of shape as well as size of the 
glenoid cavity help to predict the stability of the glenohumeral articulations as well as for designing prosthesis for shoulder arthroplasty. Glenoid cavity appears pear shaped when the notch on its anterosuperior aspect is indistinct and appear inverted comma when notch is distinct and is oval when the notch is absent [2].The wide range of movements of shoulder joint predisposes to various injuries and articular dislocation[3]. The knowledge of morphological variations of the glenoid cavity can help surgeons in shoulder arthroplasty [4].

Morphometry of glenoid cavity can help orthopaedic surgeons in cases of rotator cuff tear [5] and in shoulder reconstruction [6]. The present study aims at study of morphology of glenoid cavity, to measure various scapular and glenoid cavity dimensions and to predict glenoid cavity dimensions from other scapular dimensions.

\section{MATERIALS AND METHODS}

The present study after approval from Institutional Ethical Committee was done on 130 dry adult human scapulae (72 right and 58 left) taken from Department of Anatomy SGRDIMSR Amritsar. All the scapulae without any damage to glenoid cavity were included. Damaged scapulae were excluded from the study. The various shapes of glenoid cavity were noted and analysed. The various dimensions of the body of the scapula and glenoid cavity were measured using Digital Vernier calliper caliberated to $0.01 \mathrm{~mm}$ in accordance with Solanki [7] and Camposso et al [8]. These are 1- Maximum height of the body of scapula (distance between summit of superior angle of scapula and inferior angle) (MSH)( $A B$ as in Fig1)

2- Maximum breadth of the body of scapula ( distance between lowest point of glenoid cavity and point of intersection of the spine to the medial border)(MSW)(CD as in Fig 1)

3- Maximum glenoid cavity height (distance between supraglenoid tubercle and lowest point on glenoid cavity) (MGH)(GH as in Fig2)

4- Maximum glenoid cavity width I (distance between anterior and posterior rim) (MGWI) (EF as in Fig2)
5- Glenoid cavity width II (anteroposterior diameter of upper half of the glenoid cavity) (IJ as in Fig2)

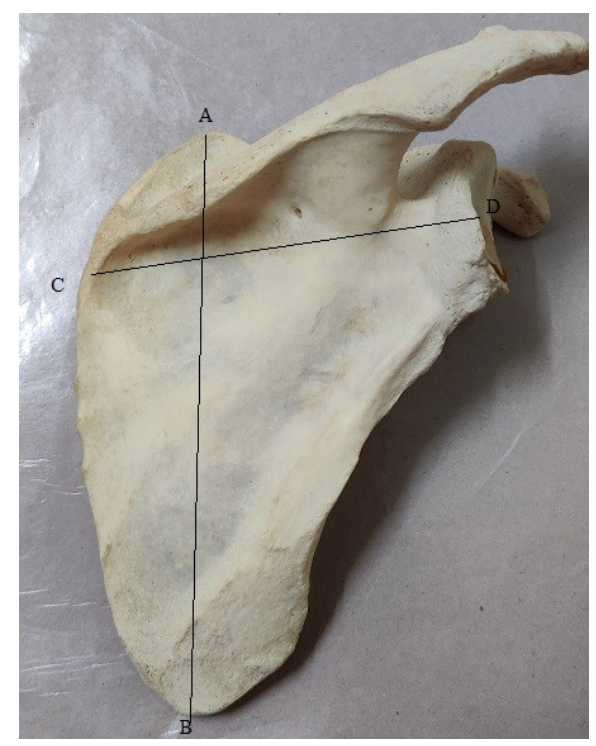

Fig. 1: Showing maximum scapular height from summit of superior angle (A) to inferior angle (B)

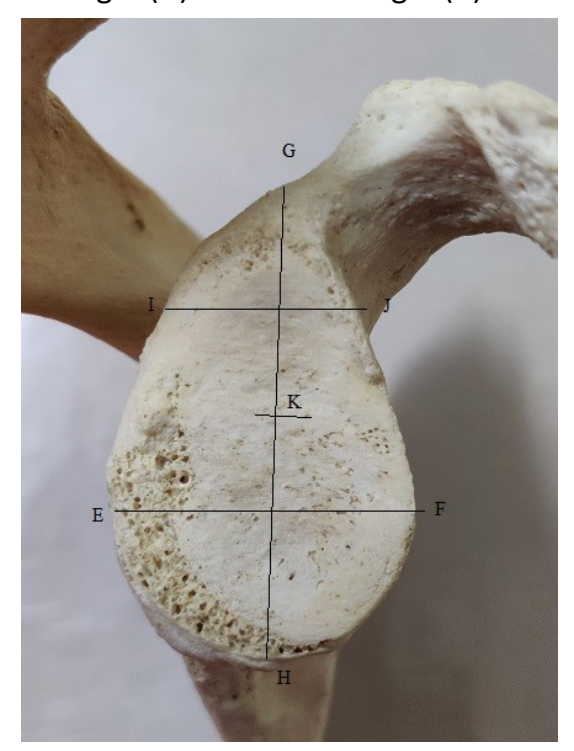

Fig. 2: Showing maximum glenoid height (MGH) from most superior point of supraglenoid tubercle(G) to inferior angle of scapula(H), maximum width of glenoid cavity (EF) as MGW1 perpendicular to maximum glenoid height, anteroposterior diameter of the glenoid cavity of upper half of the glenoid cavity (IJ).K represent the midpoint of maximum glenoid height.

\section{Following two indicics were noted}

1-Scapular index-maximum scapular width (MSW)/ maximum scapular height (MSH) multiplied by 100

2-Glenoid cavity index- maximum glenoid widthl(MGWI)/maximum glenoid height(MGH) multiplied by 100

To predict the dimensions of glenoid cavity from scapular dimensions all the factors were 
analysed using regression statistics. The data was analysed using IBM SPSS Statistics (version 21 IBM, Armonk New York)

\section{RESULTS AND DISCUSSION}

Three types of shapes of Glenoid cavity were noted and shown as Table 1.

Mean MSH calculated was $142.45 \pm 2.32 \mathrm{~mm}$ with $143.75 \pm 9.95 \mathrm{~mm}$ on the right side and $141.05 \pm 13.03 \mathrm{~mm}$ on left side. Mean MSW was $102.65 \pm 0.21 \mathrm{~mm}$ with $102.34 \pm 3.4 \mathrm{~mm}$ on the right side and $103.05 \pm 8.12 \mathrm{~mm}$ on the left side. Mean glenoid height was $39.25 \pm 6.56 \mathrm{~mm}$ as seen by Kwon et al [9] with $38.78 \pm 5.29 \mathrm{~mm}$ on the right side and $39.06 \pm 6.75 \mathrm{~mm}$ on the left side. Mean glenoid width was $23.82 \pm 2.11 \mathrm{~mm}$ as seen by Churchill et al [6] and as $23.12 \pm 2.13 \mathrm{~mm}$ on the right side and as $23.21 \pm 1.65 \mathrm{~mm}$ on the left side. There was no significant difference in scapular index as well as glenoid index on right and left side. Regression formula for estimation of MGH and MGW from scapular dimensions in the present study in North Indian population is

$\mathrm{MGH}=15.03+0.16 \mathrm{MSH}(\mathrm{R} 2=0.304)$
( $\mathrm{p}$ value $<0.001)$
$\mathrm{MGW}=9.43+0.09 \mathrm{MSH}(\mathrm{R} 2=0.413)$
$(\mathrm{p}$ value $<0.001)$
$\mathrm{MGH}=14.66+0.96 \mathrm{MGW}(\mathrm{R} 2=0.591)$
( $\mathrm{p}$ value $<0.001)$

Where R2 represent coefficients of determination

The present study showed that MSH has low significant correlation while MSW has no significant correlation with any glenoid dimension. Significant positive interglenoid correlation indicates MGW will increase with the increase in $\mathrm{MGH}$ as shown by Polguj et al [14].

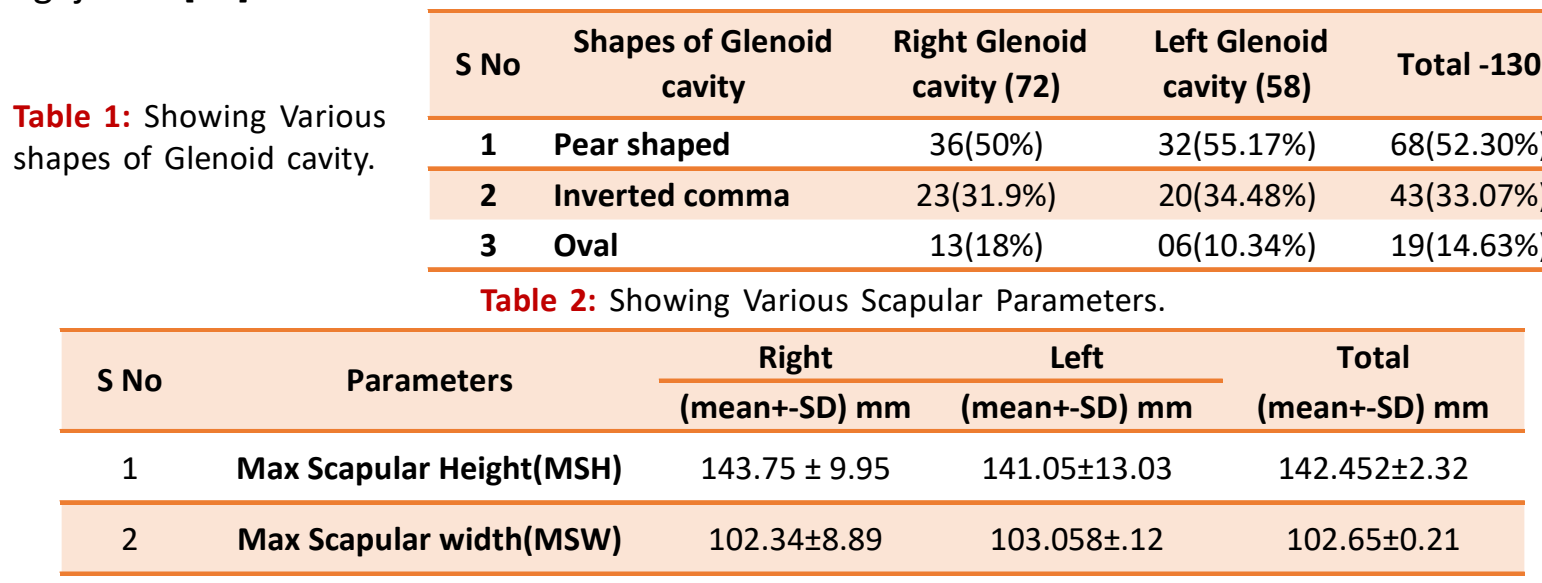

This can help to understand the causes of glenohumeral dislocations. More the difference between MGH and MGW indicates lower Glenoid index and possible GH dislocations. Most predominant shape of the glenoid cavity in the present study was pear shaped (52\%) followed by inverted comma shape (33\%) and least common was oval shaped (14\%) as seen in other studies done in Indian population $[10,11]$ as compared to the study which showed comma shaped as most common and pear

shaped as second most common shape in Egyptian population[12]. Mean glenoid index in the present study was calculated as $60.43 \pm 5.43 \%$, and as $60.62 \pm 5.11 \%$ on the right side and $60.12 \pm 4.78 \%$ on the left side, with minimum of $53 \%$ and maximum as $86.8 \%$ as compared to mean glenoid index given by Dhindsa and Singh[13] $(70.37 \pm 4.08 \%$ on right side and $68.59+4.36 \%$ on the left side), Polguj et al[14] (as combined $72.355 \pm .55 \%$ ), Akhtar et al[15] ( $66.13 \pm 8.67 \%$ on right side and $66.73 \pm 7.47 \%$ on the left side) and Singh et al [16] $69.87 \pm 1.54 \%$ on right side and $70.44 \pm 7.59 \%$ o the left side) and Tiwari et al[17] $(66.94 \pm 6.47 \%$ on right side and $68.04 \pm 4.66 \%$ on left side), Hassanein [18] $(73.67 \%$ on right side and $76.71 \%$ on the left side).A positive correlation was seen to exist between scapular height and glenoid dimensions and also between maximum glenoid height and maximum glenoid width in the present study as seen by Aigbogun et al[19]. Glenoid index towards $50 \%$ or lower means narrower the glenoid cavity and glenoid index of $80-89 \%$ indicates round glenoid cavity. Both these conditions lead to glenohumeral dislocations [19]. 
Table 3: Showing Scapular Index (SI).

\begin{tabular}{ccccccc}
\hline S No & Scapular Index & Right side $-\mathbf{7 2}$ & \% age Right side & Left side-58 & \% age Left side & Total \\
\hline 1 & $57-<61$ & 8 & $\mathbf{1 1 . 1 1}$ & $\mathbf{2}$ & $\mathbf{3 . 4 4}$ & $\mathbf{1 0}$ \\
\hline 2 & $61-<65$ & 13 & $\mathbf{1 8 . 0 5}$ & $\mathbf{7}$ & $\mathbf{1 2 . 0 6}$ & $\mathbf{2 0}$ \\
\hline 3 & $65-<69$ & 18 & $\mathbf{2 5}$ & $\mathbf{2 0}$ & $\mathbf{3 4 . 4 8}$ & $\mathbf{3 8}$ \\
\hline 4 & $69-<73$ & 27 & $\mathbf{3 7 . 5}$ & $\mathbf{2 2}$ & $\mathbf{3 7 . 9 3}$ & $\mathbf{4 9}$ \\
\hline 5 & $>73$ & 6 & $\mathbf{8 . 3 3}$ & $\mathbf{7}$ & $\mathbf{1 2 . 0 6}$ & $\mathbf{1 3}$ \\
\hline
\end{tabular}

Table 4: Various Glenoid Cavity Parameters.

\begin{tabular}{ccccc}
\hline \multirow{2}{*}{ S No } & Parameters & Right side & Left side & Total \\
\cline { 3 - 5 } & Max Glenoid Height (MGH) & $39.78 \pm 5.29$ & $37.06 \pm 6.75$ & $38.77 \pm 3.15$ \\
\hline 1 & MaxGlenoid Width1 (MGW 1) & $23.12 \pm 2.13$ & $23.21 \pm 1.65$ & $23.82 \pm 2.11$ \\
\hline 3 & Max Glenoid Width 2 (MGW11) & $14.12 \pm 2.02$ & $15.30 \pm 2.11$ & $14.78 \pm 9.11$ \\
\hline
\end{tabular}

Table 5: Glenoid Index.

\begin{tabular}{|c|c|c|c|c|c|}
\hline Glenoid Index & Right SideNo (72) & Right Side \% age & Left Side No (58) & Left Side \% & Total $\mathbf{- 1 3 0}$ \\
\hline $49 \%$ & - & - & - & - & - \\
\hline $50-59 \%$ & 4 & 5.55 & 6 & 9.23 & 10 \\
\hline $60-69 \%$ & 31 & 43.05 & 37 & 56.92 & 68 \\
\hline $70-79 \%$ & 27 & 37.05 & 11 & 18.96 & 43 \\
\hline $80-89 \%$ & 10 & 13.88 & 4 & 6.15 & 9 \\
\hline$>90 \%$ & - & - & - & - & - \\
\hline
\end{tabular}

\section{CONCLUSION}

The present study will help to determine the glenoid cavity dimensions from other scapular measurements like height and width in North Indian population. This can guide the orthopaedic surgeons in glenoid reconstruction operations.

\section{ABBREVIATIONS}

MSH- Maximum scapular height

MSW- Maximum scapular width

MGH- Maximum glenoid height

MGW I- Maximum glenoid width I

MGW II- Maximum glenoid width II

\section{Author/s Contributions:}

Seema Sehmi- Procuring scapulae, taking the dimensions of scapulae, applying statistics

Anupama Mahajan- Rechecking the data \& validation

\section{Conflicts of Interests: None}

\section{REFERENCES}

[1]. Ludewig PM and Reynolds JF. The association of scapular kinematics and glenohumeral joint pathologies. J Orthop Sports Phys Ther. 2009;39:90-104.
[2]. Prescher A, Klumpen T. The Glenoid cavity notch and its relation to the shape of Glenoid cavity of the scapula. J Anat. 1997;190:457-60.

[3]. Quillen DM, Wuchner M, Hatch RL. Acute shoulder Injuries. Am Fam Physician.2004;70:1947-54.

[4]. Renjindra GK, Ubbaida SA, Kumar VV. The glenoid cavity: its morphology and clinical significance. Int J Biol Med Res. 2016;7:5552-5.

[5]. Shimozono Y, Arai R, Matsuda S. The dimensions of the scapula glenoid in Japanese rotator cuff tear patients. Clin Orthop Surg.2017;9:207-212.

[6]. Churchill RS, Brems JJ, Kotschi H. Glenoid Size, inclination and version: an anatomical study. J Shoulder Elbow Surg.2001; 10(4): 327-32.

[7]. Solanki BS. The Angles of Scapula. J Anat Soc India. 1979; 28(1): 16-21.

[8]. Compobasso CP, Vella G, Introna F. Using Scapular Measurements in Regression Formulae for the estimation of Stature. Boll Soc Ital Biol Sper. 1998; 74 (7-8); 75-82.

[9]. Kwon YW, Powell KA, Brems JJ, Iannotti JP.Use of three dimensional computed tomography for the analysis of the glenoid anatomy. J Shoulder Elbow Surg. 2005;14(1):85-90.

[10]. Rajput HB,Vyas KK, Shroff BD. A Study of Morphological Patterns of Glenoid cavity of scapula. Natl J Med Res. 2012; 2(4):504-7.

[11]. Gamal Hamed ESH. Morphometry of Glenoid fossa in Adult Egyptian Scapulae.Int J Anat Res.2015; $3(2): 1138-42$. 
[12]. Wael Amin NED and Mona Hassan MA. A Morphometric Study of the patterns and Variations of the Acromian and Glenoid Cavity of the scapulae in Egyptian population. J Clin Diag Res. 2015; 9(8): 8-11.

[13]. Dhindsa GS and Singh Z. A study of Morphology of the Glenoid Cavity. J Evol Med Dent Sci. 2014; 3(25): 7036-43.

[14]. Polguj M, Jedrzejeski KS, Podgorski M, Topol M. Correlation between morphometry of the suprascapular notch and anthropometric measurements of the scapula. Folia Morphol. 2011; 70: 109-115.

[15]. Akhtar MJ, Kumar B, Fatima N, Kumar V. Morphometric analysis of glenoid cavity of dry scapulae and its role in shoulder prosthesis. Int J Res Med Sci. 2016; 4(7): 2770-76.

[16]. Singh A, Singh A, Agarwal P, Gupta R. A Morphological and Morphometric Study of Glenoid Fossa of Scapula and its Implication in Shoulder Arthroplasty. Int J Anat Radiol Surg.2019; 8(3): A006A009.
[17]. Tiwari V, Tiwari S, Das SS, Vasudeva N. Geometric Morphometry of Glenoid Cavity in dry adult scapulae and its surgical implications. IJSR. 2018; 7(1): 70-73.

[18]. Hassanein GH. Morphometry of Glenoid fossa in adult Egyptian Scapulae. Int J Anat Res. 2015; 3: 1138-1142.

[19]. Aigbogun EO, Oladipo GS, Oyakhire MO, Ibeachu PC. Morphometry of the glenoid cavity and its correlation with selected geometric measurement of the scapula. Bang J Med Sci.2017; 16 (4):572-79.

How to cite this article:

Seema Sehmi, Anupama Mahajan. Determination of dimensions of Glenoid cavity from other scapular parameters in North Indian Population. Int J Anat Res 2022;10(1):8216-8220. DOI: 10.16965/ ijar.2021.188 